\title{
Thermally-enhanced spectral indices to discriminate burn severity in Mediterranean forest ecosystems
}

C. Quintano, A. Fernández-Manso, P. García-Llamas, V. Fernández-García, J. M. Fernández-Guisuraga, et al.

C. Quintano, A. Fernández-Manso, P. García-Llamas, V. Fernández-García, J. M. Fernández-Guisuraga, E. Marcos, S. Suarez-Seoane, L. Calvo, "Thermally-enhanced spectral indices to discriminate burn severity in Mediterranean forest ecosystems," Proc. SPIE 10767, Remote Sensing and Modeling of Ecosystems for Sustainability XV, 107670N (18 September 2018); doi: 10.1117/12.2319851

EviE Event: SPIE Optical Engineering + Applications, 2018, San Diego, California, United States 


\title{
Thermally-enhanced spectral indices to discriminate burn severity in Mediterranean forest ecosystems
}

\author{
C. Quintano*a , A. Fernández-Manso ${ }^{\mathrm{b}}$, P. García-Llamas ${ }^{\mathrm{c}}$, V. Fernández-García ${ }^{\mathrm{c}}$, J.M. Fernández- \\ Guisuraga $^{\mathrm{c}}$, E. Marcos ${ }^{\mathrm{c}}$, S. Suarez-Seoane ${ }^{\mathrm{c}}, \mathrm{L} . \mathrm{Calvo}^{\mathrm{c}}$
}

${ }^{a}$ Electronic Technology Department, Sustainable Forest Management Research Institute, University of Valladolid-Spanish National Institute for Agricultural and Food Research and Technology (INIA), Francisco Mendizábal, 1, 47014-Valladolid, Spain; ${ }^{\mathrm{b}}$ Agrarian Science and Engineering Department, University of León, Avenida de Astorga s/n, 24400-Ponferrada, Spain; ${ }^{\mathrm{c} A r e a}$ of Ecology, Faculty of Biological and Environmental Sciences, University of León, 24071-León, Spain

\begin{abstract}
Fires are a problematic and recurrent issue in Mediterranean forest ecosystems. Accurate discrimination of burn severity level is fundamental for the rehabilitation planning of affected areas. Though fieldwork is still necessary for measuring post-fire burn severity, remote sensing based techniques are being widely used to predict it because of their computational simplicity and straightforward application. Among them, spectral indices classification (especially difference Normalized Burn Ratio - $\mathrm{dNBR}$ - based ones) may be considered the standard remote sensing based method to distinguish burn severity level. In this work we show how this methodology may be improved by using land surface temperature (LST) to enhance the standard spectral indices. We considered a large wildfire in August 2012 in North Western Spain. The Composite Burn Index (CBI) was measured in 111 field plots and grouped into three burn severity levels. Relationship between Landsat 7 Enhanced Thematic Mapper (ETM+) LST-enhanced spectral indices and CBI was evaluated by using the normalized distance between two burn severity levels and spectral dispersion graphs. Inclusion of LST in the spectral index equation resulted in higher discrimination between burn severity levels than standard spectral indices $(0.90,8.50$, and 17.52 NIR-SWIR Temperature version 1 vs $0.60,2.83$, and 6.46 NBR). Our results demonstrate the potential of LST for improving burn severity discrimination and mapping. Future research, however, is needed to evaluate the performance of the proposed LST-enhanced spectral indices in other fire regimes, and forest ecosystems.
\end{abstract}

Keywords: Burn severity, LST, Mediterranean ecosystem, forest fires, CBI, spectral indices

\section{INTRODUCTION}

Fires are a problematic and recurrent issue in Mediterranean forest ecosystems ${ }^{1}$. Accurate discrimination of burn severity level is fundamental for the rehabilitation planning of affected areas ${ }^{2}$. Remote sensing based techniques are increasingly being used to predict burn severity because of their computational simplicity and straightforward application ${ }^{3}$. Fieldwork, however, is still necessary to calibrate the remote sensing algorithms. Composite Burn Index (CBI) ${ }^{4}$ has been identified as a standard measurement. It was initially proposed for calibration and validation of remote sensing products of burn severity in Western United States and has been adapted to different regions ${ }^{5,6}$. Among the remote sensing based methods, spectral indices classification (in particular difference Normalized Burn Ratio -dNBR- based ones) may be considered the standard remote sensing based method to distinguish burn severity level.

Though the mentioned spectral indices are based exclusively on reflective bands, thermal spectral domain has demonstrated its validity for discriminating burn severity. Spectral indices from Landsat TM and ETM + enhanced with brightness temperature slightly improved burned area estimation (see 12,13). A new proposed thermally enhanced spectral from MODIS/ASTER airborne simulator data showed a moderately high value of the separability index indicating the potential of thermal wavelengths to discriminate post-fire damage (see 14). Harris et al. (2011) ${ }^{15}$ analyzed

Remote Sensing and Modeling of Ecosystems for Sustainability XV, edited by Wei Gao,

Ni-Bin Chang, Jinnian Wang, Proc. of SPIE Vol. 10767, 107670 N • (c) 2018 SPIE

CCC code: $0277-786 X / 18 / \$ 18 \cdot$ doi: $10.1117 / 12.2319851$ 
the validity of these thermally enhanced spectral indices for burn severity discrimination and compared them to commonly used spectral indices. One Land Surface Temperature (LST) enhanced spectral index showed the highest performance. Quintano et al. (2015) ${ }^{16}$ reported that post-fire LST could distinguish statistically two burn severity levels in Mediterranean large fires. Additionally, previous studies ${ }^{17,18,19,20,21}$ showed as well the relationship between LST and fire. In this context, our study aims to demonstrate that thermally enhanced spectral indices from Landsat ETM + data are suitable to discriminate burn severity in Mediterranean forest ecosystems.

\section{MATERIAL}

\subsection{Study area}

Castrocontigo, our study area, is located in northwestern Spain (Figure 1). This small mountain range has an average slope of $10 \%$ and elevation ranges above sea level between 850 to 2,100 m. The Third Spanish National Forest Inventory indicates that the area was covered by Pinus pinaster Ait. (73\%), by Pinus nigra Arm. (3\%), by Pinus sylvestris L. (2\%), by Quercus ilex L. (7\%), by Quercus pyrenaica Willd (5\%) and by shrubs (10\%) (Erica australis L., Calluna vulgaris (L.) Hull, Chamaespartium tridentatum (L.) P.E. Gibbs, Halimium alyssoides Lam and Genista florida L.). The climate is Mediterranean with an average annual rainfall between 650 and $900 \mathrm{~mm}$ and two- three months of dryness in the summer. Soil in this area is very sandy and acidic $(\mathrm{pH}=5.5)$ with low organic matter content ${ }^{22}$. In August 2012 there was a large fire, which burned $117.75 \mathrm{~km}^{2}$ for three days (between August 19-21, when a heat wave affected the study site).

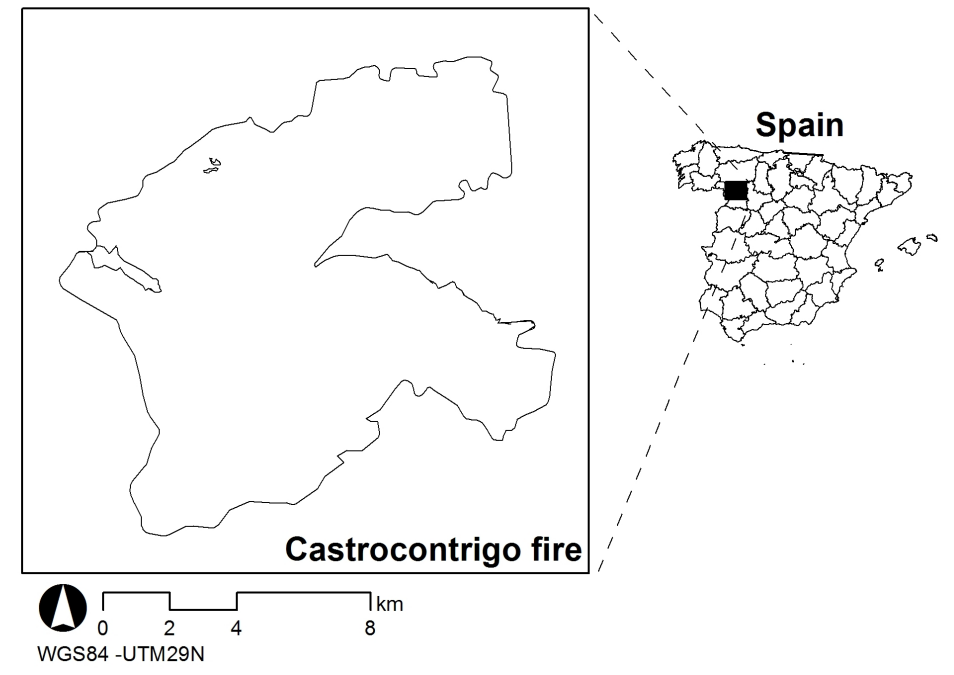

Figure 1. Study area location.

\subsection{Datasets}

CBI was measured in a total of 111 plots 9-12 weeks after the wildfire (see 4 for a complete description). The plots were located in areas of homogeneous forest structure and fire effects and the number of plots evaluated in each burn severity class was selected according to the proportional surface included in each class, taking into account the initial official severity map ( 27 unburned plots, 8 low severity plots, 29 moderate severity plots and 47 high severity plots). Following Miller and Thode $(2007)^{11}$, we chose to place the thresholds halfway between the CBI values as general guides for low, moderate and high categories: unburned (0.00-0.09), low severity (0.10-1.24), moderate severity (1.25-2.24) and high severity $(2.25-3.00)$.

We used a post-fire Landsat 7 ETM+ scene (path/row 203/31), acquired on 6 September, 2012, downloaded from the US Geological Survey (USGS). Fortunately, the forest fire was located in the middle of the Landsat-7 ETM+ scenes and we did not locate any field plot in the affected area by the Scan Line Corrector (SCL) failure.

A digital elevation model (DEM) was used to perform the topographic normalization of the Landsat 7 ETM+ images. We utilized the Advanced Spaceborne Thermal Emission and Reflection Radiometer (ASTER) Global Digital Elevation Model Version 2 (GDEM V2) provided by USGS. 


\section{METHODS}

Firstly, the Landsat 7 ETM+ scene was preprocessed. Reflective bands were scaled to surface reflectance and thermal bands to LST. Secondly, thermal-enhanced indices were computed, we also included NBR as a reference. Finally, relationship between the thermal-enhanced indices at CBI plots was evaluated.

\subsection{Pre-processing}

A subset of the image covering the forest fire was selected (latitude / longitude coordinates: upper left corner, $42^{\circ} 20^{\prime} 38.27^{\prime \prime} \mathrm{N} / 6^{\circ} 16^{\prime} 49.51^{\prime}{ }^{\prime} \mathrm{W}$; and lower right corner 42 $13^{\prime} 59.97 \mathrm{~N} / 6^{\circ} 8^{\prime} 28,40^{\prime \prime} \mathrm{W}$ ). The subset image was topographically normalized ${ }^{23}$ and atmospherically corrected ${ }^{24}$ and reflective bands were scaled to surface reflectance ${ }^{25}$. Thermal bands, first converted to radiance, were scaled to brightness temperature, following the equation and coefficients proposed by Chander et al. (2009) ${ }^{25}$. Next, brightness temperature was transformed into surface temperature by using the generalized single-channel algorithm developed by Jiménez-Muñoz and Sobrino $(2003)^{26}$ and updated by Jiménez-Muñoz et al. (2009) ${ }^{27}$. Atmospheric water vapor content values were obtained from MODIS product MOD05 and land surface emissivity was estimated from the red band reflectivity and the proportion of vegetation cover, following a semi-empirical NDVI-based method (see 28 and 29). As band 6H saturated in some pixels of LST images near to the forest fire date, we used band $6 \mathrm{~L}$ to compute the definitive LST images.

\subsection{Thermal-enhanced indices and burn severity}

Thermal-enhanced indices were computed following equations on Table 1. In particular, we evaluated Normalized Burn Ratio $^{4}$ (NBR), Normalized Difference Vegetation Index Thermal ${ }^{13}$ (NDVIT), Soil Adjusted Vegetation Index Therma ${ }^{13}$ (SAVIT), Normalized Burn Ratio Thermal ${ }^{12}$ (NBRT), Char Soil Index Thermal ${ }^{13}$ (CSIT), Vegetation Index Number 6 Thermal $^{12}$ (VI6T), NIR-SWIR-Temperature version $1^{14}$ (NSTv1), and NIR-SWIR-Temperature version $2^{14}$ (NSTv2). Next, after applying a mean $3 \times 3$ filter to the considered spectral indices, the digital values for the field plots surveyed were extracted for analysis.

Boxplots used as spectral dispersion graphs allowed us to evaluate which burn severity level can be discriminated from others. The boxplots illustrated minimum and maximum values, of the quartiles (Q1, 25\%, lower edge of the box; Q2, $50 \%$; and Q3, 75\%, top edge of the box), median (Q2, central line of the box), and the atypical values and distribution symmetry, allowing for the identification of potential confusions (overlaps) between the burn severity levels. In addition, the inter-class statistical separability between each two contiguous classes $\left(\mathrm{d}_{\mathrm{hm}}\right.$ : high and moderate; $\mathrm{d}_{\mathrm{ml}}$ : moderate and low; $\mathrm{d}_{\mathrm{lu}}$ : low and unburned) was also measured using the normalized distance $\mathrm{d}_{\mathrm{ij}}$, defined as

$$
d_{i j}=\frac{\left|\mu_{i}-\mu_{j}\right|}{\sigma_{i}+\sigma_{j}}
$$

where $\mu_{\mathrm{i}}$ and $\mu_{\mathrm{j}}$ stand for the statistical mean for the classes ' $\mathrm{i}$ ' and ' $\mathrm{j}$ ', respectively, and $\sigma_{\mathrm{i}}$ and $\sigma_{\mathrm{j}}$ stand for the standard deviations. Values of $\mathrm{d}_{\mathrm{ij}}$ larger than one indicate good separability, whereas values smaller than one represent a large degree of histogram overlap between the two classes.

\section{RESULTS AND DISCUSSION}

Table 1 displays $\mathrm{d}_{\mathrm{hm}}, \mathrm{d}_{\mathrm{ml}}$, and $\mathrm{dl}_{\mathrm{u}}$ values. All indices, except CSIT, showed $\mathrm{d}_{\mathrm{lu}}$ higher tan one. Therefore, all spectral indices (except CSIT) should allow us to discriminate burned from unburned areas. Similarly, all indices, with the exception of CSIT displayed $\mathrm{d}_{\mathrm{ml}}$ higher than one. On the contrary, none of them presented $\mathrm{d}_{\mathrm{hm}}$ higher than one. Thus, it was only possible to differentiate two levels of burn severity (low and moderate-high) when using the proposed thermalenhanced indices. Boxplots of Figure 2 demonstrated this fact graphically. 
Table 1. Thermal-enhanced spectral indices and normalized distance between burn severity levels

\begin{tabular}{|l|l|l|l|l|l|}
\hline Index & Equation & Reference & $\mathrm{d}_{\mathrm{hm}}$ & $\mathrm{d}_{\mathrm{ml}}$ & $\mathrm{d}_{\mathrm{lu}}$ \\
\hline NBR & $\frac{\left(\rho_{\text {NIR }}-\rho_{\text {SWIR }}\right)}{\left(\rho_{\text {NIR }}+\rho_{\text {SWIR }}\right)}$ & Key and Benson (2006) & 0.60 & 2.83 & 6.46 \\
\hline NDVIT & $\frac{\left(\rho_{\text {NIR }}-\rho_{R} T_{b}\right)}{\left(\rho_{\text {NIR }}+\rho_{R} T_{b}\right)}$ & Smith et al. (2007) & 0.22 & 2.26 & 3.79 \\
\hline SAVIT & $\frac{\left(\rho_{\text {NIR }}-\rho_{R} T_{b}\right)(1+L)}{\left(\rho_{\text {NIR }}+\rho_{R} T_{b}+L\right)}$ & Smith et al. (2007) & 0.36 & 7.03 & 15.37 \\
\hline NBRT & $\frac{\left(\rho_{\text {NIR }}-\rho_{\text {SWIR }} T_{b}\right)}{\left(\rho_{\text {NIR }}+\rho_{\text {SWIR }} T_{b}\right)}$ & Holden et al. (2005) & 0.13 & 2.97 & 9.24 \\
\hline CSIT & $\frac{\rho_{\text {NIR }}}{\rho_{\text {SWIR }} T_{b}}$ & & 0.15 & 0.46 & 0.90 \\
\hline VI6T & $\frac{\left(\rho_{\text {NIR }}-T_{b}\right)}{\left(\rho_{\text {NIR }}+T_{b}\right)}$ & Smith et al. (2007) & 0.12 & 2.93 & 6.35 \\
\hline NSTv1 & $\frac{\left(\rho_{\text {NIR }}-\rho_{\text {SWIR }}\right)}{\left(\rho_{\text {NIR }}+\rho_{\text {SWIR }}\right)} L S T$ & Holden et al. (2005) & & & \\
\hline NSTv2 & $\frac{\left(\rho_{\text {NIR }}-\rho_{\text {SWIR }}-L S T\right)}{\left(\rho_{\text {NIR }}+\rho_{\text {SWIR }}+L S T\right)}$ & Veraverbeke et al. (2011) & 0.62 & 2.91 & 6.84 \\
\hline
\end{tabular}

NBR: Normalized Burn Ratio; NDVIT: Normalized Difference Vegetation Index Thermal; SAVIT: Soil Adjusted Vegetation Index Thermal; NBRT: Normalized Burn Ratio Thermal; CSIT: Char Soil Index Thermal; VI6T: Vegetation Index Number 6 Thermal; NSTv1: NIR-SWIR-Temperature version 1; NSTv2: NIR-SWIR-Temperature version 2; $\rho_{\mathrm{R}}$ : red reflectance $\left(\right.$ ETM+ band 3); $\rho_{\mathrm{NIR}}$ : NIR reflectance (ETM+ band 4); $\rho_{\text {SwIR }}$ : SWIR reflectance (ETM+ band 7); $T_{b}$ : brightness temperature; LST: Land Surface Temperature; L: soil constant set to $0.5 ; \mathrm{d}_{\mathrm{hm}}$ : normalized distance between high and moderate burn severity levels; $\mathrm{d}_{\mathrm{ml}}$ : normalized distance between moderate and low burn severity levels; $\mathrm{d}_{\mathrm{lu}}$ : normalized distance between low burn severity level and unburned.

Thermal-enhanced spectral indices enabled us to distinguish two burn severity levels (low and moderate-high) instead of the three levels initially proposed. Discrimination of only two severity levels has been also reported by other remote sensing based studies ${ }^{30,31,11}$. Given that perhaps the most common reason for studying burn severity is to target areas for recovery $^{30}$, differentiating the highest severity levels from the rest of the burn severity levels may provide enough information for forest managers.

SAVIT, NBRT, NSTv2 and specially NSTv1 presented $\mathrm{d}_{\mathrm{ml}}$ and $\mathrm{d}_{\mathrm{lu}}$ values higher than NBR, suggesting a higher capacity for burn severity discrimination of thermal-enhanced indices than conventional ones. In this way, our results agree with other authors' findings (see 12, 13, 14 and 15). 

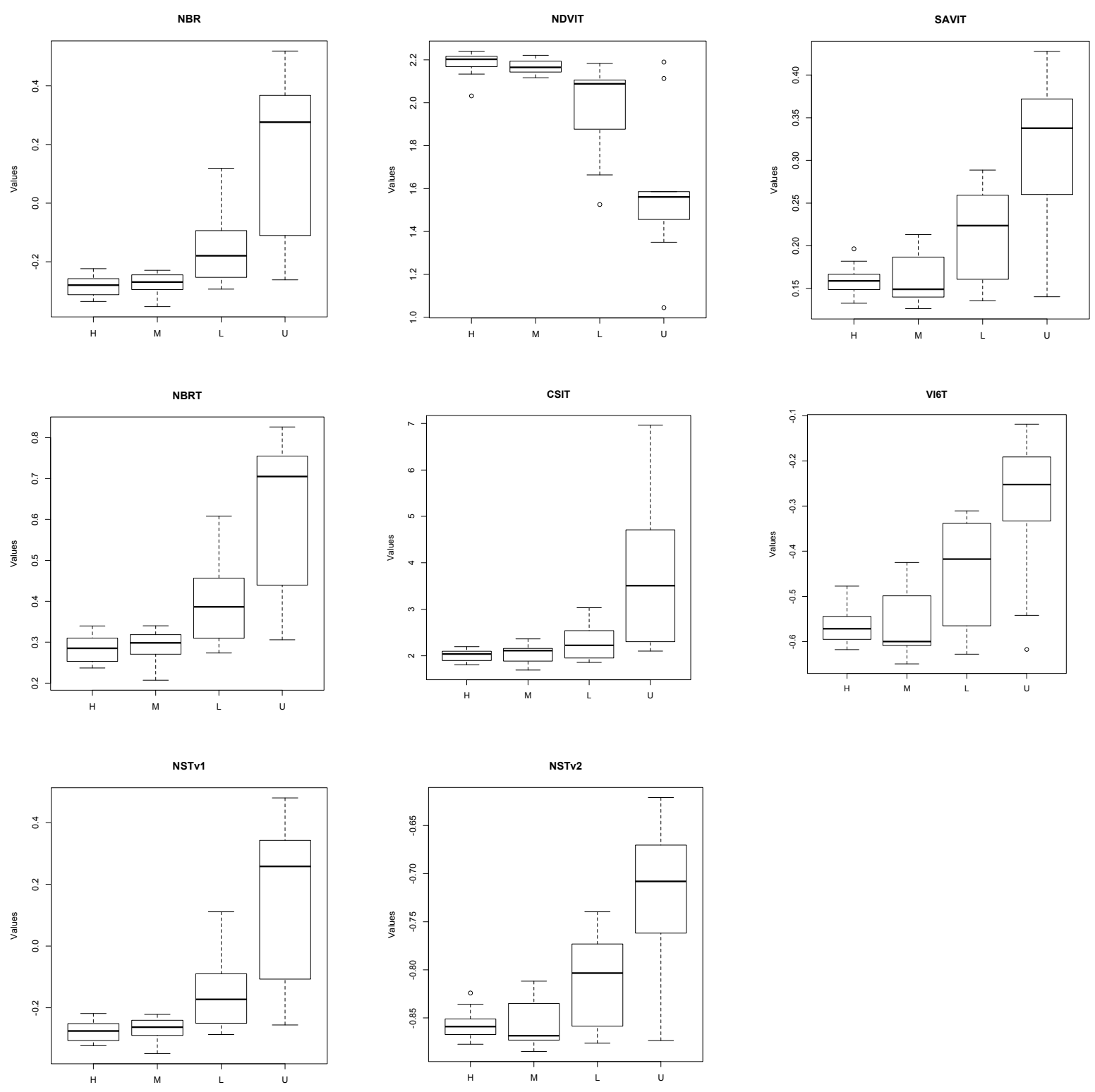

Figure 2: Spectral dispersion graphs (boxplots) for the tested thermal-enhanced spectral indices

NBR: Normalized Burn Ratio; NDVIT: Normalized Difference Vegetation Index Thermal; SAVIT: Soil Adjusted Vegetation Index Thermal; NBRT: Normalized Burn Ratio Thermal; CSIT: Char Soil Index Thermal; VI6T: Vegetation Index Number 6 Thermal; NSTv1: NIR-SWIR-Temperature version 1; NSTv2: NIR-SWIR-Temperature version 2; H; high burn severity level; M; moderate burn severity level; H; low burn severity level; U: unburned class

\section{CONCLUSION}

We analyzed the performance of thermal-enhanced spectral indices to assess burn severity in Mediterranean forest ecosystems, considering as study area a large forest fire in north-western Spain. Post-fire burn severity level (unburned, low, moderate and high) was measured in 111 field plots by CBI. Normalized distance and boxplots suggested that the thermal-enhanced indices could differentiate accurately two levels of burn severity with higher accuracy than NBR. These results demonstrate the potential of thermal-enhanced indices for assessing burn severity in Mediterranean ecosystems. Forest managers could benefit from the use of the thermal-enhanced indices, and in particular of NSTv1 for 
estimating burn severity assessment as an effective tool to define post-fire management strategies. The performance of the proposed spectral indices should be, however, evaluated in other fire regimes and vegetation types.

\section{ACKNOWLEDGMENTS}

This study was financially supported by the Spanish Ministry of Economy and Competitiveness, and the European Regional Development Fund (ERDF), in the framework of the GESFIRE (AGL2013-48189-C2-1-R) and FIRESEVES (AGL2017-86075-C2-1-R) projects; and by the Regional Government of Castilla y León within the framework of the FIRECYL (LE033U14) and SEFIRECYL (LE001P17) projects. The authors would like to thank the Autonomous Government of Castilla and León for sharing their information about the forest fires.

\section{REFERENCES}

[1] San-Miguel-Ayanz, J., Durrant, T., Boca, R., Libertá, G., Boccacci, F., Di-Leo, M., López-Pérez, J., and Schulte, E., "Forest Fires in Europe, Middle East and North Africa 2015", Joint Research Centre Technical Reports. EUR 28148 EN (ISBN 978-92-79-62959-4) (2016)

[2] Brewer, C.K., Winne, J.C., Redmond, R.L., Opitz, D.W., and Mangrich M.V., "Classifying and Mapping Wildfire Severity: A Comparison of Methods", Photogrammetric Engineering and Remote Sensing, 71, $1311-1320(2005)$

[3] Chuvieco, E., "Fundamentals of Satellite Remote Sensing: An Environmental Approach", Second Edition, CRC press, ISBN 97814987280582016, (2016)

[4] Key, C.H., and Benson, N.C. "Landscape Assessment: ground measure of severity, the Composite Burn Index; and remote sensing of severity, the Normalized Burn Ratio", in D.C. Lutes; R.E. Keane; J.F. Caratti; C.H. Key; N.C. Benson; S. Sutherland; and L.J. Gangi. "FIREMON: Fire Effects Monitoring and Inventory System", USDA Forest Service, Rocky Mountain Research Station, Ogden, UT. Gen. Tech. Rep. RMRS-GTR-164-CD: LA 1-51. (2006).

[5] Epting, J., Verbyla, D.L., and Sorbel, B., "Evaluation of remotely sensed indices for assessing burn severity in interior Alaska using Landsat TM and ETM+", Remote Sensing of Environment, 96, 328-339 (2005)

[6] Kasischke, E.S., Turetsky, M.R., Ottmar, R.D., French, N.H.F., Hoy, E.E., and Kane, E.S., "Evaluation of the composite burn index for assessing fire severity in Alaskan black spruce forests", International Journal of Wildland Fire, 17, 515-526 (2008)

[7] Fang, L., and Yang, J., "Atmospheric effects on the performance and threshold extrapolation of multi-temporal Landsat derived dNBR for burn severity assessment", International Journal of Applied Earth Observation and Geoinformation, 33, 10-20 (2014)

[8] Stambaugh, M.C., Hammer, L.D., and Godfrey, R., "Performance of Burn-Severity Metrics and Classification in Oak Woodlands and Grasslands", Remote Sensing, 7, 10501-10522 (2015)

[9] Parks, S.A., Dillon, G.K, and Miller, C., "A New Metric for Quantifying Burn Severity: The Relativized Burn Ratio", Remote Sensing, 6, 1827-1844. (2014).

[10] Soverel, N.O., Perrakis, D.D.B., and Coops, N.C., "Estimating burn severity from Landsat dNBR and RdNBR indices across western Canada", Remote Sensing of Environment, 114, 1896-1909 (2010)

[11] Miller, J.D., and Thode, A.E., "Quantifying burn severity in a heterogeneous landscape with a relative version of the delta Normalized Burn Ratio (dNBR)", Remote Sensing of Environment, 109, 66-80 (2007)

[12] Holden, Z., Smith, A., Morgan, P., Rollins, M., and Gessler, P., "Evaluation of novel thermally enhanced spectral indices for mapping fire perimeters and comparisons with fire atlas data", International Journal of Remote Sensing, 26, 4801-4808 (2005)

[13] Smith, A., Drake, N., Wooster, M., Hudak, A., Holden, Z., and Gibbons, C., "Production of Landsat ETM+ reference imagery of burned areas within Southern African savannahs: Comparison of methods and application to MODIS", International Journal of Remote Sensing, 28, 2753-2775 (2007)

[14] Veraverbeke, S., Harris, S., and Hook, S., "Evaluating spectral indices for burned area discrimination using MODIS/ASTER (MASTER) airborne simulator data", Remote Sensing of Environment, 115, 2702-2709 (2011) 
[15] Harris, S., Veraverbeke, S., and Hook, S., "Evaluating Spectral Indices for Assessing Fire Severity in Chaparral Ecosystems (Southern California) Using MODIS/ASTER (MASTER) Airborne Simulator Data", Remote Sensing, 3, 2403-2419 (2011)

[16] Quintano, C., Fernández-Manso, A., Calvo, L., Marcos, E., and Valbuena, L., "Land surface temperature as potential indicator of burn severity inforest Mediterranean ecosystems", International Journal of Applied Earth Observation and Geoinformation, 36, 1-12 (2015)

[17] Lambin, E., Goyvaerts, K., and Petit, C., "Remotely-sensed indicators of burning efficiency of savannah and forest fires", International Journal of Remote Sensing, 24, 3105-3118 (2003)

[18] Veraverbeke, S., Van de Kerchove, R., Verstraeten, W., Lhermitte, S., and Goossens, R., "Fire-induced changes in vegetation, albedo and land surface temper-ature assessed with MODIS" In: Remote Sensing for Science, Education, and Natural and Cultural Heritage: Proceedings of the EARSeL Symposium 2010, pp.431-438 (2010)

[19] Vlassova, L., Pérez-Cabello, F., Rodrigues, M., Montorio, R., and García-Martín, A., "Analysis of the relationship between land surface temperature and wildfire severity in a series of landsat images", Remote Sensing, 6, 6136-6162 (2014)

[20] Wendt, C., Beringer, J., Tapper, N., and Hutley, L., "Local boundary-layer development over burnt and unburnt tropical savanna: an observational study", Meteorology, 124, 291-304 (2007)

[21] Veraverbeke, S., Verstraeten, W.W., Lhermitte, S., Van de Kerchove, R., and Goossens, R., "Assessment of post-fire changes in land surface temperature and surface albedo, and their relation with fire-burn severity using multitmeporal MODIS imagery", International Journal of Wildland Fire, 21, 243-256 (2012)

[22] Calvo, L., Santalla, S., Valbuena, L., Marcos, E., Tárrega, R., and Luis-Calabuig E., "Post-fire natural regeneration of a Pinus pinaster forest in NW Spain," Plant Ecology, 197, 81-90 (2008)

[23] Teillet, P.M., Guindon, B., and Goodenough, D.G., "On the slope-aspect correction of multispectral scanner data", Canadian Journal of Remote Sensing 8, 84-106 (1982)

[24] Chavez Jr., P.S., "Image-based atmospheric corrections - revisited and improved", Photogrammetric. Engineering and Remote Sensing, 62, 1025-1036 (1996)

[25] Chander, G., Markham, B.L., and Helder, D.L., "Summary of current radiometric calibration coefficients for Landsat MSS, TM, ETM+, and EO-1 ALI sensors", Remote Sensing of Environment, 113, 893-903 (2009)

[26] Jiménez-Muñoz, J.C., and Sobrino, J.A., "A generalized single-channel method for retrieving land surface temperature from remote sensing data", Joournal of Geophysical Research, 108, 4688-4695 (2003)

[27] Jiménez-Muñoz, J.C., Cristobal, J., Sobrino, J.A., Soria, G., Ninyerola, M., and Pons, X., "Revision of the single-channel algorithm for land surface temperature retrieval from Landsat thermal-infrared data", IEEE Transactions on Geoscience and Remote Sensing, 47, 339-349 (2009)

[28] Sobrino, J.A., and Raissouni, N., "Toward remote sensing methods for landcover dynamic monitoring: application to Morocco," International Journal of Remote Sensing, 21, 353-366 (2000)

[29] Sobrino, J.A., Jiménez-Muñoz, J.C., Sòria, G., Romaguera, M., Guanter, L., Moreno, J., Plaza, A., and Martínez, P., "Land surface emissivity retrieval from different VNIR and TIR sensors", IEEE Transactions on Geoscience and Remote Sensing, 48, 316-327 (2008)

[30] Cocke, A.E., Fulé, P.Z. and Crouse, J.E., "Comparison of Burn Severity Assessments Using Differenced Normalized Burn Ratio and Ground Data." International Journal of Wildland Fire, 14, 189-198 (2005)

[31] Tanase, M., de la Riva, J. and Pérez-Cabello, F., "Estimating Burn Severity in Aragón Pine Forest using Optical Based Indices”, Canadian Journal of Forest Research, 41, 863-872 (2011) 